\title{
Role of Mesenchymal Stem Cells (MSC) in the Management of Brain Stroke
}

\author{
Ramesh Teegala* and Kirmani Natukula \\ Department of Neurosurgery, India \\ *Corresponding author: Ramesh Teegala, Department of Neurosurgery, ASRAM Hospital, Andhra Pradesh, India \\ Submission: 監 August 31, 2017; Published: 監 September 19, 2017
}

\begin{abstract}
Cerebro vascular Accident (CVA) also commonly known as brain stroke leads to death of brain cells. There are limitations in the effective management of stroke due to lack of definitive treatment measures. In selective cases, interventional radiological and surgical procedure may reduce or prevent the progression of disease. Medical management mainly aimed at long term prevention of stroke. There are no proven medical or surgical measures to rescue the damaged neurons of CNS origin. Mesenchymal stem cells (MSCs) have emerged as a promising approach for the replacement of lost neurons by multiple unique properties of MSCs like neo angiogenesis, stimulating endogenous neurogenesis, autocrine effect, migration, inflammatory milieu and reducing glial scar formation. MSCs are heterogeneous cells with fibroblast-like nature. They can be isolated from nearly all human tissues, including, but not limited to, placenta, umbilical cord, adipose tissue, bone marrow, skeletal muscle and heart. In this mini review, we summarize importance of Mesenchymal stem cells in the Management of Brain Stroke.
\end{abstract}

Keywords: Brain stroke; Cerebro vascular accident; Mesenchymal stem cells

\section{Introduction}

Cerebro vascular Accident (CVA) also commonly known as brain stroke or attack is one of the commonest causes of mortality after central nervous system diseases. According to the World Health Organization (WHO) 15 million people suffer from brain stroke worldwide each year. Of these many, five million die and another five million are permanently disabled [1]. According to the recent literature, developing countries are harboring major stroke load of the world and one in every five females and one in every six males above 55 years are prone to stroke [2]. The major concern with developing nations is that, there is a steady incline in the incidence rate when compared with industrialized western countries over the past 30 years where a steady decline was observed. This is due to changing habits and life style. The risk factors that are most commonly associated with ischemic stroke are hypertension, diabetes, smoking, alcohol and family history. Broadly there are two kinds of stroke conditions like: ischemic and hemorrhagic stroke. In ischemic stroke, blood supply to particular part of brain is jeopardized and subsequently lack of essential oxygen and nutrient supply and finally cell death. In case of hemorrhagic stroke, there is rupture of particular blood vessel or its associated pathologies like aneurysm [3], arterio venous malformations (AVM) or cavernomas [4] etc leading to formation of blood clot in the brain and also loss of adequate oxygenation [5] and nutrient supply. These degraded blood products liberates many secondary cellular mediators which enhances further cell damage [5,6]. Brain and spinal cord constitutes central nervous system (CNS). The CNS does not have repairable capacity and once the neuron of damaged, it's lost forever. This is the main reason for extensive morbidity and mortality associated with CNS damage and stroke related conditions. Currently available literature did not document definitive cure for neuronal death [7]. Some amount of cell repair from area of "penumbra" can be achieved with timely intervention. That is also called "golden hour" in the management of stroke. If one can restore the brain circulation with in golden hour, permanent brain damage can be reduced significantly. The time limit for the golden hour is less than 3 hours [8,9]. In Indian scenario, there are many limitations in controlling the stroke in golden hour due to lack of adequate skilled personnel, timely report to the hospital and lack of uniform medical facilities like interventional neuroradiology and advanced neurosurgical setup at the peripheral centers. For decades, extensive research and clinical approaches to combat stroke have focused on the vascular aspects of cerebral ischemia due to its high incidence and mortality. Therapeutic advances in neurosurgical and neuro interventions including carotid endarterectomy, thrombolytic therapy, anticoagulation and ant platelet agents for thromboembolic conditions, and endovascular interventions like embolectomy, stenting and coiling etc along with the treatment of risk factors such as hypertension, diabetes and hyperlipemia, have had significant positive outcome on the morbidity and mortality of stroke patients. Regenerative therapy or neuromodulation therapy is one more promising option for stroke management Cell-based therapy has recently been evaluated as a promising modality for patients with fixed neurologic deficits after stroke. Findings from 
Dr. Gary Steinberg, professor and chair of neurology at Stanford University School of Medicine in Palo Alto, CA, and colleagues a small number of stroke patients who have been treated with stem cells and the results showed much positive claiming that the finding leads to "life-changing treatments" for stroke patients. Another finding from the same researchers that stem cell transplantation improved patients' recovery when administered up to 3 years after stroke [10]. Another study with CD34+ cells a type of stem cell shows the promising effect to aid stroke recovery during a 6 months follow-up [11]. Nowadays Stem cell based therapy is a promising modality for promoting neuroregeneration after brain injury and can be potentiated by supportive pharmacological therapy. The potential uses of stem cells are to replace damaged cells and tissues according to their source. Stem cells can be obtained from blastocyst cells (embryonic stem cells (ESCs), adult stem cells (bone marrow derived stem cells (BMSCs) derived from peripheral blood or other tissues like adipose tissue), umbilical cord blood cells, and induced pluripotent stem cells (IPSCs). Bone marrow mononuclear cells (BM-MNCs), bone marrow derived mesenchymal stem stromal cells (BMMSCs), umbilical cord stem cells (UCSCs), and neural stem cells (NSCs) are the most promising cells for recovery after cerebral ischemia. Of all types of stem cell-based source, as discussed above Mesenchymal stem cells (MSCs) have emerged as a promising approach for the treatment of ischemic stroke. MSCs are a multipotent stem cell type and they can be harvested and transplanted autologously (i.e. from the same individual). MSCs are good candidates for the treatment of stroke as they are easily obtained and have a strong safety profile because of minimal immune rejection and avoiding complications such graft versus host disease (autologous transfusion), improving functional outcome through neurogenesis and angiogenesis. Using allogeneic cells allows for the ability to manipulate the cells without an extensive waiting period between cell harvest and transplantation and provides a cost-effective, off the shelf product. This feature is also attractive if multiple dosing is required for the therapeutic benefit to persist. Since ischemic and traumatic injuries are acquired disorders rather than progressively degenerative diseases, it is likely that a single dose will be sufficient. In addition, adult MSCs do not have the tumorigenicity risks like that of pluripotent stem cells. To support this there are a number of preclinical data showing that transplantation of MSC promotes functional recovery of cerebral ischemia of stroke origin or Traumatic Brain Injury (TBI). Transplanted MSCs enhance host repair and healing primarily through direct and indirect cell-cell mediated neurotropic effect [12]. Other advantages with MSC, they secrete both soluble (cytokines, growth factors) and insoluble (extracellular matrix proteins) factors that promote neural cell survival and regeneration (neuro, angio and synaptogenesis) through paracrine signaling to neural and immune cells. The wide tissue distribution and multipotent differentiation of MSCs together with the observed reparative effects of infused MSCs in many clinical and preclinical models strongly suggest a critical role of MSCs in injured neuronal healing. They are believed to be responsible for growth, wound healing, and replacing cells that are lost Because of these functions, they have been shown to be effective in the treatment of stroke. Due to immunological properties of MSCs, they are now considered to be foremost candidate cells for regenerative therapy especially in neurological disorders [13,14]. In recent studies by Suda et al. [15], Zhao et al. [16], Kaengkan et al. [17] found that combination therapy with neuroprotective agents could enhances the amelioration of ischemic brain damage in rats. Also team found that antioxidants and MSCs as a combination caused a better MSCs migration to the ischemic brain and decreases the infarct volume, neurological defect and apoptosis when compared with combination versus MSCs alone. There are few more clinical trials in progress to study the effects of stem cell transplantation for stroke whose results are waiting. There are multiple challenges before the MSC come into routine clinical practice like optimization of cell type, cell survivability, dosage, and timing etc. Re-establishment of lost path during cell replacement is one of the most important steps facing in cell-based therapy, and this could be achieved by combining stem cell therapy with new approaches such as optogenetics [18]. Cell based therapy is one of the most exciting recent developments in stroke research. It's still in its infancy, but these findings could lead to newer treatment options for stroke in the future.

\section{References}

1. www.emro.who.int/health-topics/stroke-cerebrovascular-accident/ index.html

2. Seshadri S, Beiser A, Kelly-Hayes M, Kase CS, Au R, et al. (2006) The lifetime risk of stroke: Estimates from the Framinhgham Study. Stroke 37(2): 345-350.

3. Zhu XL, Chan MSY, Poon WS (1997) Spontaneous intracranial hemorrhage: which patients need diagnostic cerebral angiography? A prospective study of 206 cases and review of the literature. Stroke 28(7): 1406-1409.

4. Brown RDJ, Flemming KD, Meyer FB, Cloft HJ, Pollock BE, et al. (2005) Natural history, evaluation, and management of intracranial vascular malformations. Mayo Clin Proc 80: 269-281.

5. Hayman L, Taber K, Ford J, Bryan R (1991) Mechanisms of MR signal alteration by acute intracerebral blood: old concepts and new theories. AJNR Am J Neuroradiol 12: 899-907.

6. Zamani AA, Rumbaugh CL, Wang A, Tsai FY (1995) Cerebrovascular Disease Imaging and Interventional Treatment Options. Igaku-Shoin, New York, USA, pp. 232-247.

7. Silver J, Schwab ME, Popovich PG (2015) Central Nervous System Regenerative Failure: Role of Oligodendrocytes, Astrocytes, and Microglia. Cold Spring Harb Perspect Biol 7(3): a020602.

8. Mendelow AD, Gregson BA, Fernandes HM, Murray GD, Teasdale GM, et al. (2005) Early surgery versus initial conservative treatment in patients with spontaneous supratentorial intracerebral haematomas in the International Surgical Trial in Intracerebral Haemorrhage (STICH): a randomised trial. Lancet 365(9457): 387-397.

9. Mendelow AD, Gregson BA, Rowan EN, Murray GD, Gholkar A, et al. (2013) Early surgery versus initial conservative treatment in patients with spontaneous supratentorial lobar intracerebral haematomas (STICH II): a randomised trial. Lancet 382(9890): 397-408.

10. Steinberg GK, Kondziolka D, Wechsler LR, Lunsford LD, Coburn ML, et al. (2016) Clinical outcomes of transplanted modified bone marrow-derived mesenchymal stem cells in stroke: a phase 1/2a study. Stroke 47: 18171824.

11. Banerjee S, Bentley P, Mohammad H, Marley S, Davis J, et al. (2014) IntraArterial Immunoselected CD34+ Stem Cells for Acute Ischemic Stroke. Stem Cells Transl Med 3(11): 1322-1330. 
12. Parr AM, Tator CH, Keating A (2007) Bone marrow-derived mesenchymal stromal cells for the repair of central nervous system injury. Bone Marrow Transplant 40(7): 609-619.

13.Hoogduijn MJ, Popp F, Verbeek R, Masoodi M, Nicolaou A, et al. (2010) The immunomodulatory properties of mesenchymal stem cells and their use for immunotherapy. Int Immunopharmacol 10(12): 1496-1500.

14. Mauri M, Lentini D, Gravati M, Foudah D, Biella G, et al. (2012) Mesenchymal stem cells enhance GABAergic transmission in co-cultured hippocampal neurons. Mol Cell Neurosci 49(4): 395-405.

15.Suda S, Shimazaki K, Ueda M, Inaba T, Kamiya N, et al. (2011) Combination therapy with bone marrow stromal cells and FK506 enhanced amelioration of ischemic brain damage in rats. Life Sci 89(1): 50-56.
16. Zhao Y, Guan Y, Xu Y, Li Y, Wu W, et al. (2012) Sodium ferulate combined with bone marrow stromal cell treatment ameliorating rat brain ischemic injury after stroke. Brain Res 1450: 157-165.

17. Kaengkan P, Baek SE, Choi YW, Kam KY, Kim JY, et al. (2013) Combination effect of p-hydroxybenzyl alcohol and mesenchymal stem cells on the recovery of brain damage in a rat model of brain ischemia. Animal Cells and Systems 17(3): 160-169.

18. Chau M, Zhang J, Wei L, Yu SP (2016) Regeneration after stroke: Stem cell transplantation and trophic factors. Brain Circulation 2: 86-94. 